\title{
Emergency Planning Zones Estimation for Karachi-2 and Karachi-3 Nuclear Power Plants using Gaussian Puff Model
}

\author{
Sümer Şahin ${ }^{1}$ and Muhammad $\mathrm{Ali}^{2,3}$ \\ ${ }^{1}$ Near East University, Faculty of Engineering, Turkish Republic of Northern Cyprus, Yakın Doğu Bulvarl, \\ PK:99138 Lefkoşa/KKTC, Mersin 10, Turkey \\ ${ }^{2}$ ATILIM University, Faculty of Engineering, Department of Mechanical Engineering, 06836 İncek, Gölbaşı, Ankara, Turkey \\ ${ }^{3}$ Directorate of Nuclear Power Engineering-Reactor (DNPER), Directorate of Nuclear Safety (DNS), \\ P.O. Box 3140, Islamabad, Pakistan \\ Correspondence should be addressed to Sümer Şahin; sumer.sahin@neu.edu.tr
}

Received 6 May 2016; Revised 25 June 2016; Accepted 5 July 2016

Academic Editor: Arkady Serikov

Copyright (C) 2016 S. Şahin and M. Ali. This is an open access article distributed under the Creative Commons Attribution License, which permits unrestricted use, distribution, and reproduction in any medium, provided the original work is properly cited.

Emergency planning zones (PAZ and UPZ) around the Karachi-2 and Karachi-3 nuclear power plants (K-2/K-3 NPPs) have been realistically determined by employing Gaussian puff model and Gaussian plume model together for atmospheric transport, diffusion, and deposition of radioactive material using onsite and regional data related to meteorology, topography, and landuse along with latest IAEA Post-Fukushima Guidelines. The analysis work has been carried out using U.S.NRC computer code RASCAL 4.2. The assumed environmental radioactive releases provide the sound theoretical and practical bases for the estimation of emergency planning zones covering most expected scenario of severe accident and most recent multiunit Fukushima Accident. Sheltering could be used as protective action for longer period of about 04 days. The area about $3 \mathrm{~km}$ of K-2/K-3 NPPs site should be evacuated and an iodine thyroid blocking agent should be taken before release up to about $14 \mathrm{~km}$ to prevent severe deterministic effects. Stochastic effects may be avoided or minimized by evacuating the area within about $8 \mathrm{~km}$ of the K-2/K-3 NPPs site. Protective actions may become more effective and cost beneficial by using current methodology as Gaussian puff model realistically represents atmospheric transport, dispersion, and disposition processes in contrast to straight-line Gaussian plume model explicitly in study area. The estimated PAZ and UPZ were found $3 \mathrm{~km}$ and $8 \mathrm{~km}$, respectively, around K-2/K-3 NPPs which are in well agreement with IAEA Post-Fukushima Study. Therefore, current study results could be used in the establishment of emergency planning zones around K-2/K-3 NPPs.

\section{Introduction}

Emergency planning zones (EPZs) are established around nuclear power plants in order to implement prompt and effective protective actions and other response actions to protect the public during nuclear emergency situation at nuclear power plant(s). The emergency situation arises due to damage of nuclear fuel present in nuclear reactor core or in spent fuel pool of nuclear power plants. Such emergency situations may have severe health effects (deterministic and stochastic) which affect public in different ways, for example, prompt causalities, reducing their life quality, and causing physiological and socioeconomic problems. These consequences can be prevented or mitigated by implementing protective actions promptly in the designated areas, that is, emergency planning zones. The designated areas include precautionary action zone (PAZ) to reduce substantially the risk of severe deterministic effects and urgent protective action planning zone (UPZ) and to reduce substantially the risk of stochastic effects. The importance of EPZs has been demonstrated in Fukushima Accident as protective actions; that is, evacuation of public within $20 \mathrm{~km}$ and sheltering within $20-30 \mathrm{~km}$ (later on advised to evacuate voluntarily) prevented radiological consequences effectively $[1,2]$.

Emergency planning zones are estimated considering spectrum of accidents, environmental releases of radioactive materials, meteorology, and radiological doses from different exposure pathways. The consideration of spectrum of 
accident is important as some accidents have high occurrence probability with less health consequences while some accidents have low occurrence probability with high health consequences. Therefore, spectrum of accidents is considered for radioactive material environmental releases to consider both low occurrence probability accidents and high occurrence probability accidents and their health effects accordingly. The radioactive materials that enter into environment after occurrence of accident are subsequently transported, diffused, and deposited on ground according to local and regional meteorology, topography, and land-use characteristics. Then, radiological doses are calculated for potential exposure pathways, for example, cloud shine, inhalation, and ground shine in model domain area. Finally, EPZs are determined using dosimetry criteria set forth by the national and/or international nuclear regulator/agency.

Generally, straight-line Gaussian plume model (GPM) is used for estimation of EPZs because it is simple and computationally inexpensive. However, straight-line GPM may give unreasonable estimates of pollutant concentration away from the release point while it gives reasonable estimates in the vicinity of release point as these models transport pollutants "immediately" to entire modeling area. Also, routinely collected meteorological data at nuclear power plants is normally used in the estimation of EPZs. However, meteorological conditions may change drastically as pollutants move away from the release point, for example, topography effects, and thus onsite meteorological data alone may give unrealistic results. Since radiological doses depend on radioactive material quantity in the environment, therefore, onsite meteorological data in straight-line GPMs may give unrealistic radiological doses estimates.

Further, data sampling techniques (e.g., Latin Hypercube) are normally used to obtain representative meteorological data instead of calculating radiological doses for each meteorological condition (e.g., 8760 meteorological conditions in a typical year) while determining radiological doses at different percentile [3, 4]. Data sampling makes calculation computationally inexpensive and also requires low memory capacity. Since nowadays high computing machines with sufficient memory capacity are available, therefore, if all meteorological data were used, typically required in EPZs calculations, instead of data sampling, then better statistical distribution of radiological doses would be achieved.

In this study, EPZs (PAZ and UPZ) around the Karachi2 and Karachi-3 nuclear power plants (K-2/K-3 NPPs) have been determined using U.S.NRC (United States Nuclear Regulatory Commission) RASCAL 4.2 (Radiological Assessment System for Consequence Analysis) computer code [5]. U.S.NRC RASCAL 4.2 is the state-of-the-art computer code which deploys Gaussian puff model for atmospheric transportation, diffusion, and deposition of radioactive material away from its release point and Gaussian plume model in the vicinity of release point using onsite and regional data related to meteorology, topography, and land-use. The details of models and methods included in RASCAL 4.2 are given in [5]. Also, IAEA Post-Fukushima Guidelines (International Atomic Energy Agency) are implemented for the determination of EPZs in this study [5]. Following the IAEA Post-Fukushima Guidelines, $10 \%$ of nuclear reactor core volatile radioactive material is assumed to be released for 10-hour duration into the environment [6]. The radioactive material was then subsequently transported, diffused, and deposited on ground according to onsite and regional meteorology, topography, and land-use characteristics using RASCAL 4.2 atmospheric transport and dispersion model. Radiological doses through potential exposure pathways (i.e., cloud shine, ground shine, and inhalation) are calculated using ICRP-60 (International Commission on Radiological Protection) models for representative onsite and regional meteorological conditions. Finally, IAEA dosimetry criteria for EPZs are applied for the determination of EPZs for K-2/K3 NPPs.

\section{Literature Review}

Emergency preparedness and response (EPR) is the systematic methodology which ensures the capability and performance of actions required to mitigate the consequences of an emergency situation at nuclear power plants for human health and safety, quality of life, property, and the environment [6]. Emergency planning zones (EPZs), an integral part of EPR, have always been considered in nuclear industry even before 1979 TMI Accident (Three Mile Island), the most disastrous nuclear accident in operating commercial nuclear power plant history at that time. In 1978, U.S.NRC gave the idea of generic emergency planning zones which was based on spectrum of accidents, consequences, and probability [7]. Several studies addressing different aspects of radioactivity releases during nuclear emergency situation have been conducted particularly on emergency planning zones [716], radiation doses [17-20], and intervention distances for protective actions [21].

Accident scenario has profound impact on the size of emergency planning zones as each accident sequence has different probability of occurrence and corresponding health consequences. Several studies revealed that single accident sequence may not fulfill the EPR objectives efficiently [6-8]. Therefore, it is recommended to use spectrum of accident [6-8] as it results in the optimization of protective actions available to potentially highly affected areas, for example, near plant [8]. In this regard, IAEA has suggested $10 \%$ of nuclear reactor core volatile radioactive material is assumed to be released during 10-hour duration into the environment [6].

Also, atmospheric transport, diffusion, and deposition of radioactive materials from an accident depend on the surrounding meteorology, topography, and land-use characteristics and the consequences that will result. Different mathematical models are used to predict the dispersion of radioactive material in the environment, for example, Gaussian plume model, Gaussian puff model, and Lagrangian particle model. In most of the above-mentioned studies, straight-line Gaussian plume model (GPM) has been used due to its simplicity, ease of calculation, and requiring less computational time as well as low memory capacity. Straightline GPMs, however, may give unreasonable estimates of 


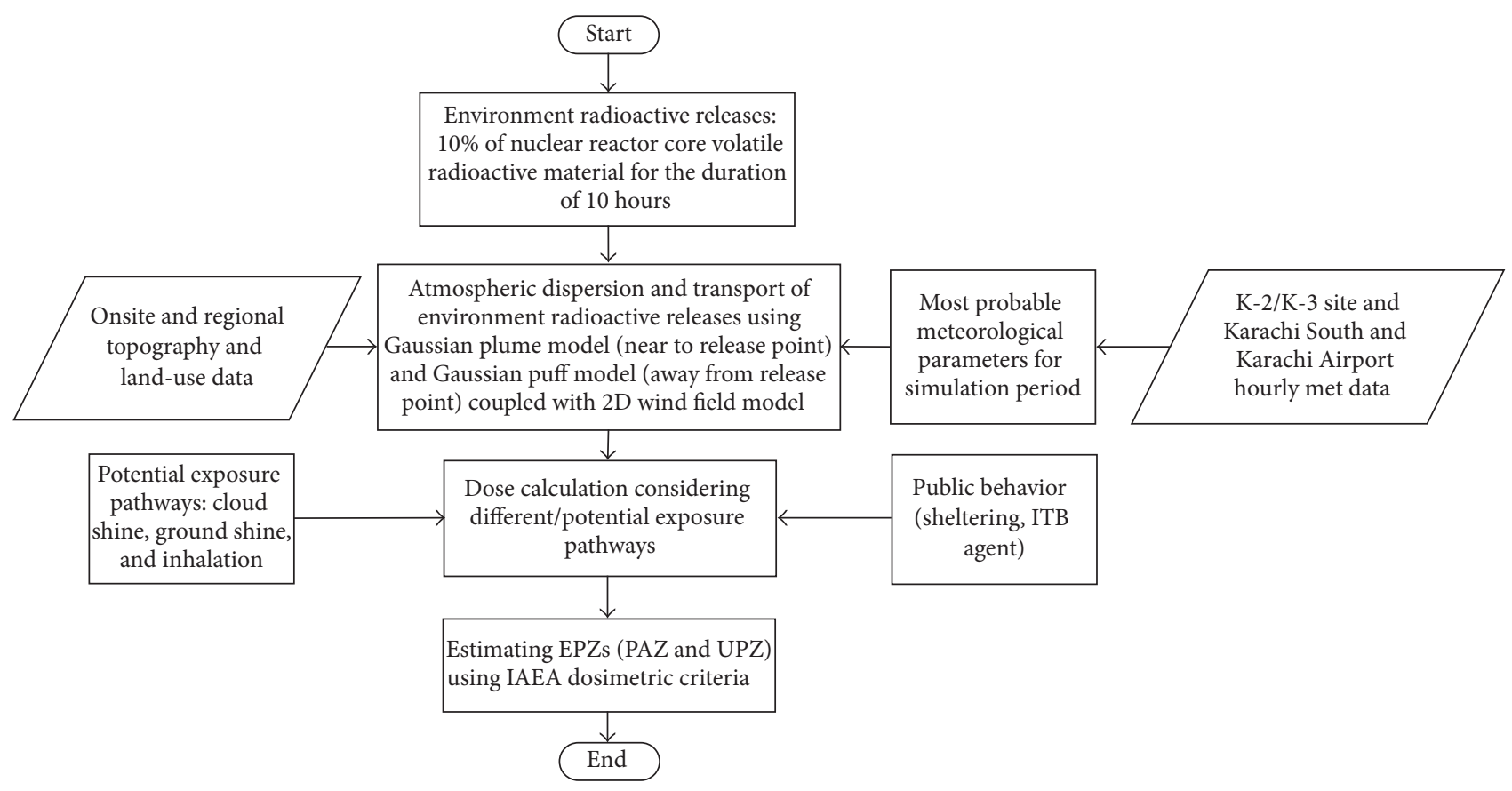

FIgURE 1: Methodology for estimation of K-2/K-3 NPPs EPZs.

pollutant concentration away from the pollutant release point as meteorology beyond $10 \mathrm{~km}$ may not remain the same [22] due to surrounding area characteristics, for example, topography, and land-use features may also significantly modify meteorological characteristics.

Recently, a study was conducted to estimate emergency planning zones using RODOS module RIMPUFF [8] which is based on Gaussian puff model [23,24]. In the referred study, meteorological data provided by German Weather Service was preferred over more accurate onsite meteorological data as the former covers the simulation area. However, more accurate meteorological data from onsite meteorological station along with meteorological data from national weather service may be better approach as it would improve the spatial and temporal representation of wind fields in the simulation area [25].

Further, in most of the above-mentioned studies, data sampling techniques have been used that select input variables such that the essential information could be acquired regarding output variables which subsequently results in efficient computation [26]. In other words, these techniques are used (e.g., Latin Hypercube) to obtain representative meteorological data instead of calculating radiological doses for each meteorological condition (e.g., 8760 meteorological conditions in a typical year) [3, 4]. However, nowadays computing machines speed and memory capacity has been drastically increased and use of data sampling might not be as much advantageous as it was when computing speed and memory capacity were limited. Therefore, statistical distribution of radiological doses may be improved if all meteorological data, typically required in EPZs calculations, is used instead of data sampling.

\section{Methodology and Model Description}

ACP1000 (renamed as Hualong-1) nuclear power plants (NPPs), $2 \times 1100 \mathrm{MW}_{\text {el }}$ pressurized water reactor (PWR) each, are being constructed near Karachi, the southern onshore city of Pakistan, and expectedly put into commercial operation in $2020 / 2021$. The nuclear power plants site is about $23 \mathrm{~km}$ northwest of Karachi having coordinates $24^{\circ} 51^{\prime} 5^{\prime \prime}$ north and $66^{\circ} 46^{\prime} 31^{\prime \prime}$ east with Sulaiman Mountains in the northwest. Within $80 \mathrm{~km}$ radius of site, two (02) national weather meteorological stations exist: Karachi South Meteorological Station at $18 \mathrm{~km}$ in east-north-east of site and Karachi Airport Meteorological Station at $40 \mathrm{~km}$ in east of site [27].

Hualong- 1 is the third generation three-loop PWR design with $3050 \mathrm{MW}_{\text {th }}$ thermal power, 18-month fuel cycle, and fuel burn-up greater than $45,000 \mathrm{MWd} / \mathrm{MT}$ of uranium. It has double containment, 60-year design life, and contains active and passive redundant safety systems [27].

In this study, EPZs (PAZ and UPZ) around $\mathrm{K}-2 / \mathrm{K}$ 3 nuclear power plants (NPPs) have been determined in accordance with IAEA Post-Fukushima Guidelines [6] using U.S.NRC RASCAL 4.2 computer code. RASCAL 4.2 is the state-of-the-art computer code designed to be used in the independent assessment of dose projections. It was developed to allow consideration of the dominant aspects of source term, transport, dose, and consequences. It evaluates releases from nuclear power plants, spent fuel storage pools and casks, fuel cycle facilities, and radioactive material handling facilities.

The flow chart of the methodology adopted in the current study is shown in Figure 1 and details are given in subsequent sections. 
3.1. Environment Radioactive Releases. It was assumed that $10 \%$ of nuclear reactor core volatile radioactive material is released at ground level into the environment. It was assumed that releases continue for 10 hours. It is the maximum expected radioactive material release into the environment following an accident that severely damages the fuel [6] and also covers the Fukushima Accident scenario $[5,8]$. The duration of 10 hours was assumed for radioactive material release although it may continue many hours after initiation of severe accident. Since shorter release period leads to larger emergency planning zones [8], therefore, 10-hour release duration would result in optimization with reference to different accident scenario. Further, containment by-pass was considered as the release pathway as it may warrant protective actions early [28]. Finally, duration of prerelease phase was assumed to be zero hour (0 hour) while in real scenario several hours would be available to take protective actions before start of severe release of radioactive material, for example, 13hour duration prerelease phase of Fukushima Accident [8].

3.2. Atmospheric Dispersion. Gaussian puff model has been employed for atmospheric transport, diffusion, and deposition of radioactive material away from release point and Gaussian plume model in the vicinity of release point. The mathematical models implemented in RASCAL 4.2 are given in (1) and (2). The complete description is given in [5].

The Gaussian puff model as implemented in RASCAL 4.2 is given below:

$$
\begin{aligned}
\frac{\chi(x, y, z)}{Q}= & \frac{1}{2 \pi^{3 / 2} \sigma_{x} \sigma_{y} \sigma_{z}} \exp \left[-\frac{1}{2}\left(\frac{x-x_{0}}{\sigma_{x}}\right)^{2}\right] \\
& \cdot \exp \left[-\frac{1}{2}\left(\frac{y-y_{0}}{\sigma_{y}}\right)^{2}\right] \\
& \cdot \exp \left[-\frac{1}{2}\left(\frac{z-z_{0}}{\sigma_{z}}\right)^{2}\right] .
\end{aligned}
$$

The straight-line Gaussian plume model as implemented in RASCAL 4.2 is given below:

$$
\frac{\chi(x, y, z)}{Q^{\prime}}=\frac{F_{y} F_{z}}{2 \pi u \sigma_{y} \sigma_{z}} .
$$

Meteorological data collected from onsite meteorological station along with meteorological data from national weather meteorological stations has been used in the analysis as it would improve the spatial and temporal representation of wind fields in the simulation area. For this study, onsite meteorological data for the years 2013-2015 along with regional meteorological historical data collected from two meteorological stations that lie about $80 \mathrm{~km}$ radius around $\mathrm{K}$ 2/K-3 site has been used.

Most probable wind direction, wind speed, and atmospheric stability class of each hour of 10-hour duration of radioactive material release have been calculated at each meteorological station. Most probable wind direction (MPWD) for the first hour of radioactive material release has been estimated through cumulative frequency distribution, taking into account the circular nature of wind data (details may be found in literature, e.g., [29]), using hourly wind direction data along with corresponding wind speed and atmospheric stability class. The MPWD along with corresponding most probable wind speed and atmospheric stability class has been used as first hour meteorology for radioactive release. Most probable wind direction shift (MPWDS) during 10-hour release has been calculated through cumulative frequency distribution using every 10 hour absolute wind direction shift data. The total wind direction shift MPWD \pm MPWDS was assumed during 10hour release period. For subsequent hours (i.e., 2nd to 10th hour of radioactive release), occurrence frequency of each wind direction in MPWD \pm MPWS span has been calculated and arranged in descending order. The first nine (09) wind directions were assumed as wind direction of subsequent hours of radioactive release. These nine (09) wind directions along with corresponding most probable wind speed and atmospheric stability have been used for subsequent hours of radioactive material release.

Elevation data in three (03) terrain grids with 22 points in $X$ and $Y$ directions in each grid with grid spacing of 1.0, 2.5, and 5.0 miles have been calculated with CALMET preprocessor TERREL [30] using Global Digital Elevation Model (GTOPO30) to account for region topography effects. Similarly, surface roughness in three (03) terrain grids with 21 points in $X$ and $Y$ directions in each grid with grid spacing of 1.0, 2.5, and 5.0 miles has been calculated using land-use/land-cover data (LULC) from ESRI (Environmental Systems Research Institute).

3.3. Radiation Doses. Cloud shine, inhalation, and ground shine pathways were considered as potential exposure pathways for PAZ while inhalation pathway was considered for UPZ. The dose conversion factors (DCFs) of ICRP60 were considered for radiation doses calculation while acute inhalation dose to red bone marrow was calculated using DCF given in IAEA EPR-D-Values 2006. The IAEA dosimetric criteria for emergency planning zones (PAZ and UPZ) have been used and the same is given in Table 1 for reference. The impacts of public behavior, that is, protective actions on the distance to which IAEA criteria (Table 1) may be exceeded, were examined according to IAEA guidelines [6]. It should be highlighted here that house sheltering was considered only for inhalation pathway assuming normal activity, that is, one-third of the time outside house (in the field) and two-thirds of the time inside house. Thyroid 50year committed dose and acute dose are very similar because of short half-life of the iodine isotopes that dominate thyroid dose and evident from IAEA Study [6]. Therefore, thyroid committed dose equivalent from inhalation has been used in this study for acute dose to thyroid.

\section{Analysis and Results}

The volatile radioactive materials of radiological significance are krypton, xenon, iodine cesium, and tellurium [31]. Therefore, $10 \%$ of these radioactive materials were released in 
TABLE 1: IAEA dosimetric criteria for emergency planning zones [6].

\begin{tabular}{|c|c|c|c|c|c|c|}
\hline \multirow{2}{*}{ Zone } & \multirow{2}{*}{$\begin{array}{l}\text { Actions taken based on plant } \\
\text { conditions to prevent the following }\end{array}$} & \multirow{2}{*}{ Dosimetric quantity } & \multirow{2}{*}{ Dose criteria } & \multicolumn{3}{|c|}{ Exposure pathway } \\
\hline & & & & Inhalation & Cloud shine & Ground shine \\
\hline \multirow{2}{*}{ PAZ } & \multirow{2}{*}{ Severe deterministic effects } & $\mathrm{AD}_{\text {red marrow }}$ & $1 \mathrm{~Gy}$ & $\mathrm{X}$ & $\mathrm{X}$ & $\mathrm{X}$ \\
\hline & & $\mathrm{AD}_{\text {fetus,inh }}$ & $1 \mathrm{~Gy}$ & $\mathrm{X}$ & & \\
\hline \multirow{2}{*}{ UPZ } & \multirow{2}{*}{ Stochastic effects } & $E_{\text {inh }}$ & $100 \mathrm{mSv}$ & $\mathrm{X}$ & & \\
\hline & & $H_{\text {fetus,inh }}$ & $100 \mathrm{mSv}$ & $\mathrm{X}$ & & \\
\hline
\end{tabular}

TABLE 2: Environment radioactive releases.

\begin{tabular}{lc}
\hline Group & Radioactivity releases $(\mathrm{Bq})$ \\
\hline Noble gases $(\mathrm{Xe}, \mathrm{Kr})$ & $2.13 \times 10^{18}$ \\
Iodine & $2.17 \times 10^{18}$ \\
Cesium & $1.46 \times 10^{17}$ \\
Tellurium & $5.89 \times 10^{17}$ \\
\hline
\end{tabular}

the environment within 10 hours as given in Table 2. These environmental radioactive releases are maximum expected activity in case of accident that severely damages the fuel. The environmental releases of noble gases and iodine groups are nearly in the same order, that is, $2.13 \times 10^{18} \mathrm{~Bq}$ and $2.17 \times 10^{18} \mathrm{~Bq}$, respectively. Cesium and tellurium group's environmental releases are lower than noble gases and iodine groups with $1.46 \times 10^{17} \mathrm{~Bq}$ and $5.89 \times 10^{17} \mathrm{~Bq}$, respectively. The radioactive releases of ${ }^{131} \mathrm{I}$ and ${ }^{137} \mathrm{Cs}$ have been given in Table 3 along with Fukushima Accident releases and one of the recent studies for comparison. It is evident from Table 3 that environmental releases in current study cover both scenarios. Since current study covers the Fukushima Accident scenario, therefore, the analysis may be considered as multiunit studies. However, it may be pointed out here that the current analysis would be refined after completion of Probabilistic Safety Assessment Level-2 study. Therefore, it may be deduced that the environmental radioactive releases considered in this study provide the sound theoretical and practical bases for the estimation of emergency planning zones as they cover the most expected scenario of severe accident as well as multiunit Fukushima Accident.

Figure 2 shows the time dependent release rate of ${ }^{131} \mathrm{I}$ and ${ }^{137} \mathrm{Cs}$, two most important radionuclides in radiological consequences, which depicts the accident progression as reactor core passes through different phases, that is, cladding failure, core melt phase, and post-vessel melt-through phase $[5,32]$. It is seen that ${ }^{131} \mathrm{I}$ and ${ }^{137} \mathrm{Cs}$ release rate to the environment at the start of release is about $4.46 \times 10^{14} \mathrm{~Bq} / 15 \mathrm{~min}$ and $5.33 \times 10^{13} \mathrm{~Bq} / 15 \mathrm{~min}$, respectively, which increases as accident progresses and attains the maximum value of $1.02 \times$ $10^{16} \mathrm{~Bq} / 15 \mathrm{~min}$ and $1.26 \times 10^{16} \mathrm{~Bq} / 15 \mathrm{~min}$ at about 3.8 hours. After about 3.8 hours, both ${ }^{131} \mathrm{I}$ and ${ }^{137} \mathrm{Cs}$ show decreasing trend as post-vessel melt-through phase has completed. It is also evident from Figure 2 that ${ }^{131}$ I decreases more rapidly than ${ }^{137} \mathrm{Cs}$ after about 3.8 hours because ${ }^{131} \mathrm{I}$ has much shorted half-life as compared to ${ }^{137} \mathrm{Cs}$. Also, the total released quantity of ${ }^{131} \mathrm{I}$ is $3.1 \times 10^{17} \mathrm{~Bq}$ which is greater than ${ }^{137} \mathrm{Cs}$

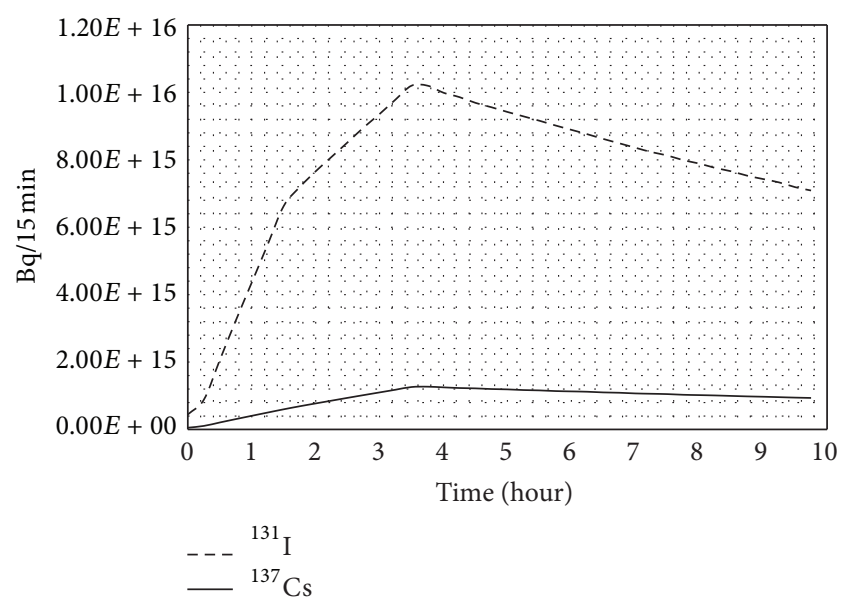

FIgURE 2: Time dependent ${ }^{131}$ I and ${ }^{137}$ Cs release rate.

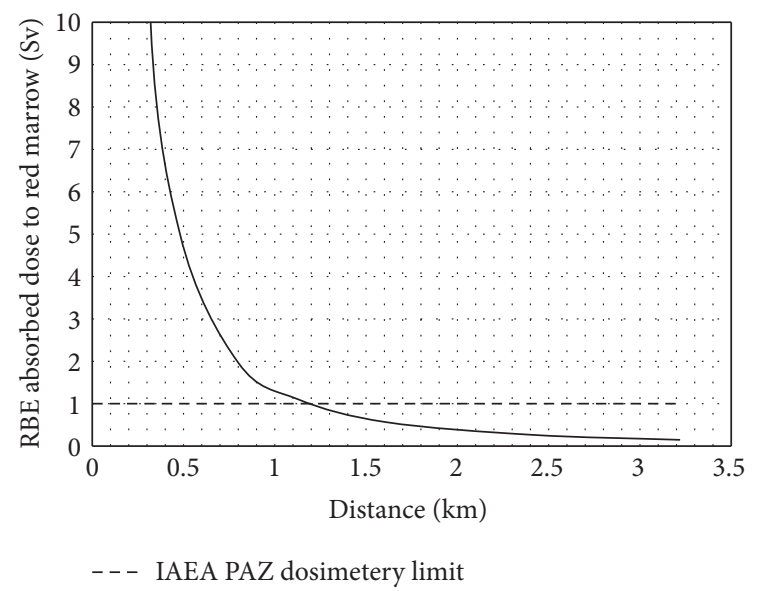

Figure 3: RBE weighted absorbed dose to red marrow from cloud shine, inhalation, and ground shine.

by the order of about 10 times, that is, $3.7 \times 10^{16}$. It is observed that specific activity of ${ }^{131} \mathrm{I}$ is greater than ${ }^{137} \mathrm{Cs}$ and ingrowth of ${ }^{131} \mathrm{I}$ is through decay of ${ }^{131} \mathrm{Te}$. Finally, at the end of simulation, that is, 10 hours, the release rate of ${ }^{131} \mathrm{I}$ and ${ }^{137} \mathrm{Cs}$ resides around $7.09 \times 10^{15} \mathrm{~Bq} / 15 \mathrm{~min}$ and $9.36 \times$ $10^{14} \mathrm{~Bq} / 15 \mathrm{~min}$, respectively.

The acute red bone marrow dose profile is shown in Figure 3, solid curve. Acute red bone marrow dose rapidly decreases along the path as plume moves away from the source. It is evident from the profile that IAEA dosimetric 
TABLE 3: Estimates of radioactive releases of different studies.

\begin{tabular}{lcc}
\hline Cases & ${ }^{131} \mathrm{I}(\mathrm{Bq})$ & ${ }^{137} \mathrm{Cs}(\mathrm{Bq})$ \\
\hline K-2/K-3 NPPs study & $3.1 \times 10^{17}$ & $3.7 \times 10^{16}$ \\
Fukushima Accident [8] & $1.1 \times 10^{17}-2.1 \times 10^{17}$ & $1.1 \times 10^{16}-2.1 \times 10^{16}$ \\
SSK 2014 study [8] & $3.1 \times 10^{17}$ & $2.9 \times 10^{16}$ \\
\hline
\end{tabular}

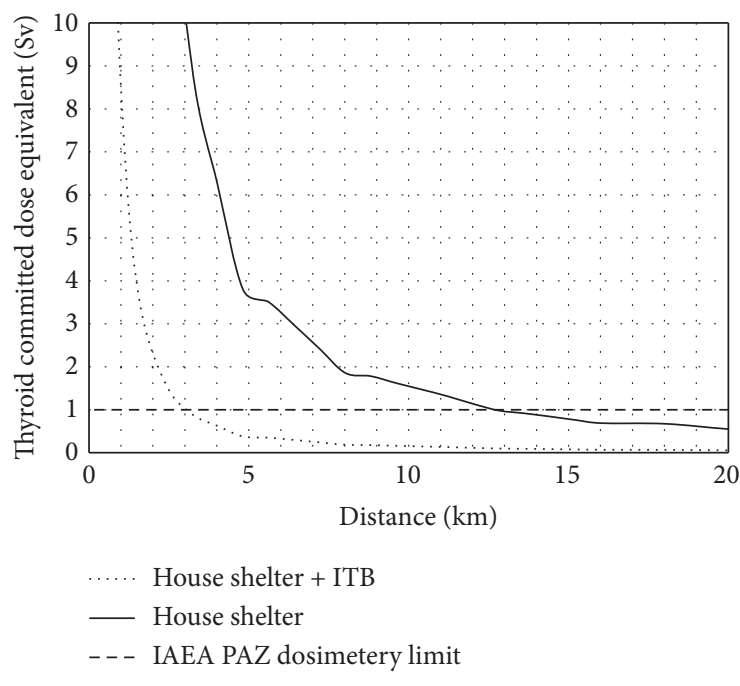

FIgURE 4: Thyroid committed dose equivalent to fetus from inhalation.

criterion of $1 \mathrm{~Sv}$ is projected to be exceeded to about a distance of $1.2 \mathrm{~km}$ which is in good agreement with IAEA Study [6]. It should be pointed out here that RASCAL 4.2 always calculates dose from ground shine pathway for 04 days. Therefore, sheltering could be used as protective action for longer period, if required, as radiological doses through ground shine pathway do not result in substantial increase in acute dose to red bone marrow. Ground shine dose depends on deposition (dry and wet) of radionuclides. In RASCAL 4.2, dry deposition is realistically modeled as dry deposition velocity change with changing meteorological conditions and surface instead of fixed velocity. Radiological doses through ground shine pathway may be increased if wet deposition (rain and snow) is considered. However, the probability of rain is very low while the probability of snow is extremely low in this region [27]. Therefore, the effect of wet deposition may be ignored as highly unlikely scenarios would reduce the number of protective measures.

Thyroid committed dose equivalent from inhalation profile has been shown in Figure 4. It shows that if ITB agent is taken before inhalation, the IAEA criterion is projected to be exceeded to about $3 \mathrm{~km}$ if pregnant woman is sheltering in a house. However, if ITB agent is not taken then the criterion is projected to be exceeded to about a distance of $14 \mathrm{~km}$ if pregnant woman is sheltering in a house. The thyroid committed dose equivalent to fetus from inhalation is in well agreement with IAEA Study [6] if pregnant woman takes ITB agent before inhalation and is sheltering in a house. However, thyroid committed dose equivalent to fetus from inhalation falls nearly half-way with IAEA Study [6] if pregnant woman

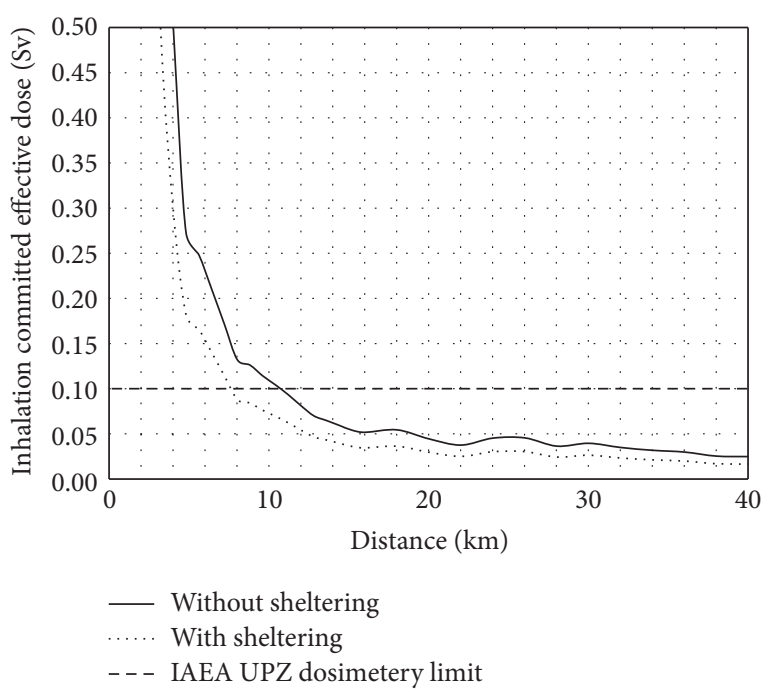

FIGURE 5: Effective dose from inhalation.

does not take ITB agent before inhalation and sheltering in a house. This comparison shows that the atmospheric transport, diffusion, and deposition characteristics of current study area are better than the area considered in IAEA Study. It should be highlighted here that RASCAL 4.2 gives more realistic results in contrast to straight-line Gaussian plume models as it modifies the wind field to account for topography and hence realistic radionuclide concentration. It is suggested that to prevent the severe deterministic effects of a severe release, the area within about $3 \mathrm{~km}$ of the K-2/K-3 NPPs should be evacuated and an iodine thyroid blocking agent taken before a release to about a distance of $14 \mathrm{~km}$. Therefore, Gaussian puff model not only gives more realistic results but also increases protective actions effectiveness as well as making them more cost effective.

The effective dose from inhalation profile is shown in Figure 5. IAEA dosimetric criterion of $100 \mathrm{mSv}$ of effective dose is projected to be exceeded from inhalation to about $8 \mathrm{~km}$ for an individual sheltering in a house and about $11 \mathrm{~km}$ without sheltering. The thyroid committed dose equivalent from inhalation profile is shown in Figure 6, with solid curve. It shows that if an ITB agent is taken before or shortly after the inhalation the criterion of $100 \mathrm{mSv}$ to the fetus is projected to be exceeded to about $14 \mathrm{~km}$ for a pregnant woman sheltering in a house. Therefore, it is inferred that in order to avoid or minimize stochastic effects for a severe release, the area within about $8 \mathrm{~km}$ of K-2/K-3 NPPs should be evacuated.

It is emphasized here that emergency planning zones should be based on realistic analysis because highly unlikely scenarios would reduce the number of protective measures and hence be not favorable of meeting the intended 


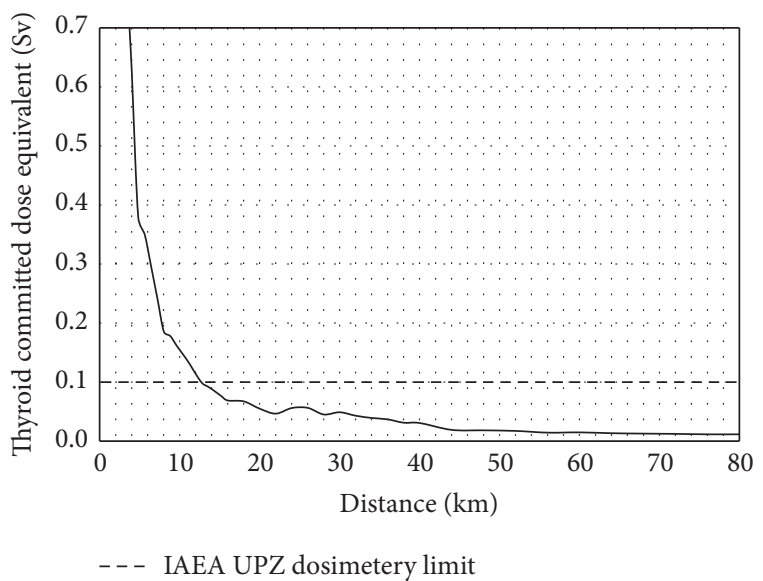

FIGURE 6: Thyroid committed dose equivalent from inhalation after taking ITB and sheltering.

objectives. Therefore, current study recommends $3 \mathrm{~km}$ and $8 \mathrm{~km}$ as PAZ and UPZ, respectively, for K-2/K-3 NPPs. The recommended PAZ and UPZ are in well agreement with IAEA guidelines [6] which suggest that the size of PAZ and UPZ could be established based on site specific analysis provided that the boundary would not be more than a factor of two less than or greater than the recommended range, that is, $3-5 \mathrm{~km}$ for PAZ and $15-30 \mathrm{~km}$ for UPZ.

\section{Conclusion}

The current study presents the application of Gaussian puff model using onsite and regional data related to meteorology, topography, and land-use along with latest IAEA Post-Fukushima Guidelines for the estimation of emergency planning zones (PAZ and UPZ) around K-2/K-3 NPPs. The environmental radioactive releases, specifically ${ }^{131} \mathrm{I}(3.1 \times$ $\left.10^{17} \mathrm{~Bq}\right)$ and ${ }^{137} \mathrm{Cs}\left(3.7 \times 10^{16} \mathrm{~Bq}\right)$, provide the sound theoretical and practical bases for the estimation of emergency planning zones as they cover the most expected scenario of severe accident, that is, $10 \%$ of nuclear reactor core volatile radioactive material as well as most recent multiunit Fukushima Accident. Also, sheltering could be used as protective action for longer period of about 04 days, if required. Further, to prevent the severe deterministic effects of a severe release, the area within about $3 \mathrm{~km}$ of K-2/K-3 NPPs should be evacuated and an iodine thyroid blocking agent should be taken before a release to about a distance of $14 \mathrm{~km}$. Moreover, stochastic effects of severe release of radioactive material may be avoided or minimized by evacuating the area within about $8 \mathrm{~km}$ of K-2/K-3 NPPs site. Protective actions may become more effective and cost beneficial by using current methodology as Gaussian puff model realistically represents atmospheric transport and dispersion process in contrast to straight-line Gaussian plume model. Therefore, it is suggested that $3 \mathrm{~km}$ and $8 \mathrm{~km}$ around K-2/K-3 NPPs may be designated as PAZ and UPZ, respectively, which are in well agreement of IAEA Post-Fukushima Guidelines.

\section{Nomenclature}

\begin{tabular}{|c|c|}
\hline $\begin{array}{l}\chi(x, y, z): \\
Q:\end{array}$ & $\begin{array}{l}\text { Concentration }\left(\mathrm{Ci} / \mathrm{m}^{3} \text { or } \mathrm{g} / \mathrm{m}^{3}\right) \\
\text { Amount of material released }(\mathrm{Ci} \text { or } \mathrm{g})\end{array}$ \\
\hline$\sigma_{x}, \sigma_{y}, \sigma_{z}:$ & Dispersion parameters $(\mathrm{m})$ \\
\hline$x_{0}, y_{0}, z_{0}:$ & Center of the puff \\
\hline$Q^{\prime}:$ & Material release rate $(\mathrm{Ci} / \mathrm{sec}$ or $\mathrm{g} / \mathrm{sec})$ \\
\hline$F_{y}, F_{z}:$ & Lateral and vertical exponential terms \\
\hline$u:$ & Wind speed $(\mathrm{m} / \mathrm{sec})$ \\
\hline ACP: & Advance Chinese PWR \\
\hline $\mathrm{AD}_{\text {fetus,inh }}$ : & Absorbed dose to fetus through inhalation \\
\hline $\mathrm{AD}_{\text {red marrow }}:$ & Absorbed dose to red marrow \\
\hline CALMET: & California meteorology \\
\hline DCFs: & Dose conversion factors \\
\hline$E_{\text {inh }}:$ & Effective dose through inhalation \\
\hline EPR: & Emergency preparedness and response \\
\hline EPZs: & Emergency planning zones \\
\hline ESRI: & Environmental Systems Research Institute \\
\hline GPMs: & Gaussian plume models \\
\hline GTOPO30: & Global 30 Arc-Second Elevation dataset \\
\hline$H_{\text {fetus,inh }}:$ & $\begin{array}{l}\text { Equivalent dose to fetus through } \\
\text { inhalation }\end{array}$ \\
\hline IAEA: & International Atomic Energy Agency \\
\hline ICRP: & $\begin{array}{l}\text { International Commission on } \\
\text { Radiological Protection }\end{array}$ \\
\hline ITB: & Iodine thyr \\
\hline K-2: & Karachi-2 \\
\hline K-3: & Karachi-3 \\
\hline $\mathrm{Kr}$ : & Kryp \\
\hline LULC: & Land-use lar \\
\hline MPWD: & e wind direction \\
\hline MPWDS: & Most probable wind direction shift \\
\hline MWd/MT: & ay per ton \\
\hline NPPs: & Nuclear power plants \\
\hline PAZ: & action zone \\
\hline PWR: & Pressurized water reactor \\
\hline RASCAL: & $\begin{array}{l}\text { Radiological Assessment System of } \\
\text { Consequence Analysis }\end{array}$ \\
\hline RBE: & Relative biological effectiveness \\
\hline RIMPUFF: & Risø model puff \\
\hline RODOS: & Real-time online decision support system \\
\hline SSK: & Strahlenschutzkommission \\
\hline TERREL: & Terrain elevation \\
\hline TMI: & Three Mile Island \\
\hline U.S.NRC: & $\begin{array}{l}\text { United States Nuclear Regulatory } \\
\text { Commission }\end{array}$ \\
\hline UP & Urgent protective action planning zone \\
\hline & Xenon \\
\hline
\end{tabular}

\section{Competing Interests}

The authors declare that they have no competing interests.

\section{References}

[1] IAEA, The Fukushima Daiichi Accident Report by the Director General, International Atomic Energy Commission, IAEA, 2015. 
[2] "Sources, Effects and Risks of Ionizing Radiation," United Nations Scientific Committee on the Effects of Atomic Radiation, Vol. 1, Annex A, 2013.

[3] T. J. Bander, "PAVAN: an atmospheric dispersion program for evaluating design-basis accidental releases of radioactive materials from nuclear power stations," Tech. Rep. NUREG/CR2858, Division of Systems Integration, Office of Nuclear Reactor Regulation, U.S. Nuclear Regulatory Commission, Washington, DC, USA, 1982.

[4] T. Haste, J. Birchley, E. Cazzoli, and J. Vitazkova, "MELCOR/MACCS simulation of the TMI-2 severe accident and initial recovery phases, off-site fission product release and consequences," Nuclear Engineering and Design, vol. 236, no. 10, pp. 1099-1112, 2006.

[5] J. V. Ramsdell Jr., G. F. Athey, S. A. McGuire, and L. K. Brandon, Rascal 4: Description of Models and Methods, 205550001, NUREG-1940, Office of Nuclear Security and Incident Response, U.S. Nuclear Regulatory Commission, Washington, DC, USA, 2012.

[6] IAEA, Actions to Protect the Public in an Emergency due to Severe Conditions at a Light Water Reactor, International Atomic Energy Commission, IAEA, Vienna, Austria, 2013.

[7] H. E. Collins, B. K. Grimes, and F. Galpin, "Planning basis for the development of state and local government radiological emergency response plans in support of light water nuclear power plants," Tech. Rep. NUREG-0396, U.S. Nuclear Regulatory Commission, 1978.

[8] Planning Areas for Emergency Response Near Nuclear Power Plants, Recommendation by the German Commission on Radiological Protection, Strahlenschutzkommission, Geschäftsstelle der Strahlenschutzkommission, Bonn, Germany, 2014.

[9] CNSC, "Study of consequences of a hypothetical severe nuclear accident and effectiveness of mitigation measures," PWGSC Catalogue CC172-119/2015E-PDF, Canadian Nuclear Safety Commission (CNSC), 2015.

[10] B. H. Ha, J. Y. Oh, and S. J. Oh, Examination of the Emergency Planning Zone (EPZ) Using Level 3 Psa Approach with Maccs2, Transactions of the Korean Nuclear Society Autumn Meeting Gyeongju, Gyeongju, Korea, 2013.

[11] H. Ting, Q. Jingyuan, L. Hong, and C. Jianzhu, "Preliminary Study on plume emergency planning zone for AP1000," Atomic Energy Science and Technology, vol. 45, no. 12, pp. 1472-1477, 2011.

[12] H.-Y. Luo, J.-H. Wang, W.-H. Li, and J.-R. Guo, "Evaluation of emergency planning zone for EPR nuclear power unit in TSNPP," Nuclear Power Engineering, vol. 31, no. 6, pp. 117-122, 2010.

[13] J. Wu, Y.-M. Yang, I.-J. Chen, H.-T. Chen, and K.-S. Chuang, "Reevaluation of the emergency planning zone for nuclear power plants in Taiwan using MACCS2 code," Applied Radiation and Isotopes, vol. 64, no. 4, pp. 448-454, 2006.

[14] I.-Y. Jeon, J. K. Lee, and J. Ki, "Evaluation of the size of emergency planning zone for the korean standard nuclear power plants," Journal of the Korean Association for Radiation Protection, vol. 28, no. 3, pp. 215-223, 2003.

[15] L.-C. Kung, C.-I. Jane, H.-Y. Hao, and C.-Y. Ching, Preliminary Study of the Emergency Planning Zone Evaluation for the Nuclear Power Plant in Taiwan by Using Maccs2 Code, vol. 1, Japan Health Physics Society, Tokyo, Japan, 2000.

[16] K. A. Solomon and W. E. Kastenberg, "Estimating emergency planning zones for the Shoreham nuclear reactor: a review of four safety analyses," Journal of Hazardous Materials, vol. 18, no. 3, pp. 269-284, 1988.

[17] R. Chang, J. Schaperow, T. Ghosh, J. Barr, C. Tinkler, and M. Stutzke, State-of-the-Art Reactor Consequence Analyses (Soarca) Report, NUREG-1935, Office of Nuclear Regulatory Research, U.S. Nuclear Regulatory Commission, Washington, DC, USA, 2012.

[18] Severe Accident Risks: An Assessment for Five U.S. Nuclear Power Plants, Vol. 1, NUREG-1150, Division of Systems Research, Office of Nuclear Regulatory Research, US Nuclear Regulatory Commission, Washington, DC, USA, 1990.

[19] M. L. Abbott, L. C. Cadwallader, and D. A. Petti, "Radiological dose calculations for fusion facilities," Tech. Rep. INEEL/EXT03-00405, Idaho National Engineering and Environmental Laboratory, Idaho Falls, Idaho, USA, 2003.

[20] A. S. Aliyu, A. T. Ramli, and M. A. Saleh, "Assessment of potential human health and environmental impacts of a nuclear power plant (NPP) based on atmospheric dispersion modeling," Atmósfera, vol. 28, no. 1, pp. 13-26, 2015.

[21] M. Hussain, S. U.-D. Khan, W. A. A. Syed, and S. U.-D. Khan, "Estimation of intervention distances for urgent protective actions using comparative approach of MACCS and InterRAS," Science and Technology of Nuclear Installations, vol. 2014, Article ID 874134, 5 pages, 2014.

[22] Ministry for the Environment, "Good practice guide for atmospheric dispersion modelling," ME 522, Ministry for the Environment, Wellington, New Zealand, 2004.

[23] T. Mikkelsen, Description of the Risø Puff Diffusion Model, Risø National Laboratory for Sustainable Energy, Technical University of Denmark, Lyngby, Denmark, 1982.

[24] "The Rodos System, Version PV6.0," Forschungszentrum Karlsruhe $\mathrm{GmbH}$, Institut für Kern-und Energietechnik (IKET), Hermann-von-Helmholtz-Platz 1, 76344 EggensteinLeopoldshafen, Germany, 2005.

[25] G. F. Athey, L. K. Brandon, and J. V. Ramsdell Jr., Rascal 4.2 Workbook, Office of Nuclear Security and Incident Response, US Nuclear Regulatory Commission, Washington, DC, USA, 2012.

[26] R. L. Iman and W. J. Conover, Sensitivity Analysis Techniques: Self-Teaching Curriculum, Sandia National Laboratories, Albuquerque, NM, USA, 1982.

[27] Pakistan Atomic Energy Commission, Environmental Impact Assessment K-2/K-3 Project, Pakistan Atomic Energy Commission, Islamabad, Pakistan, 2015.

[28] J. Kubanyi, R. B. Lavin, D. Serbanescu, B. Toth, and H. Wilkening, Risk Informed Support of Decision Making in Nuclear Power Plant Emergency Zoning, European Commission DG Joint Research Centre, Institute for Energy, 2008.

[29] K. V. Mardia and P. E. Jupp, Directional Statistics, John Wiley \& Sons, 2000.

[30] Calpuff Modeling System Version 6, User Instructions, Exponent Engineering and Scientific Consulting, California, Calif, USA, 2011.

[31] "Background and Derivation of ans-5.4 standard fission product release model," Division of Systems Integration, Office of Nuclear Reactor Regulation NUREG/CR-2507, U.S. Nuclear Regulatory Commission, Washington, DC, USA, 1982.

[32] L. Soffer, S. B. Burson, C. M. Ferrell, R. Y. Lee, and J. N. Ridgely, "Accident source terms for light-water nuclear power plants," Division of Systems Technology, Office of Nuclear Regulatory Research NUREG-1465, U.S. Nuclear Regulatory Commission, Washington, DC, USA, 1995. 

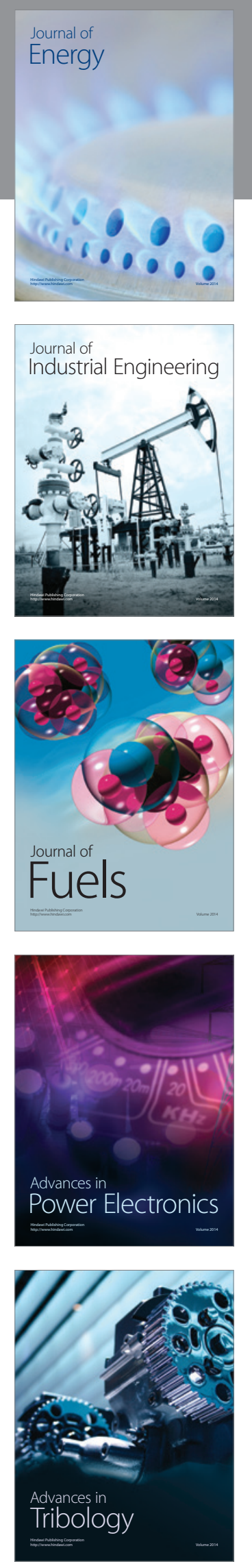
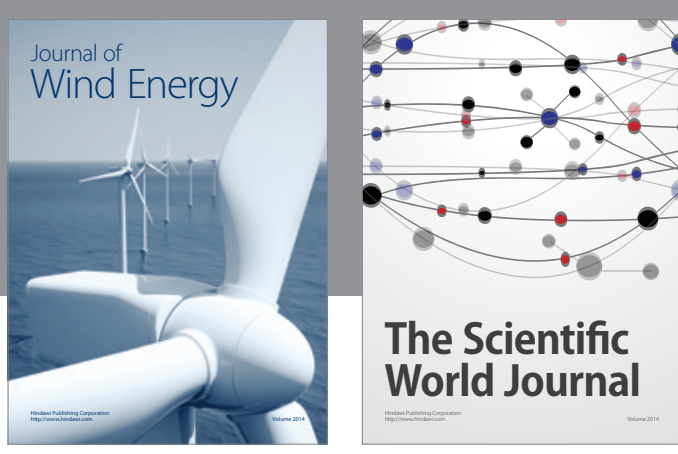

The Scientific World Journal
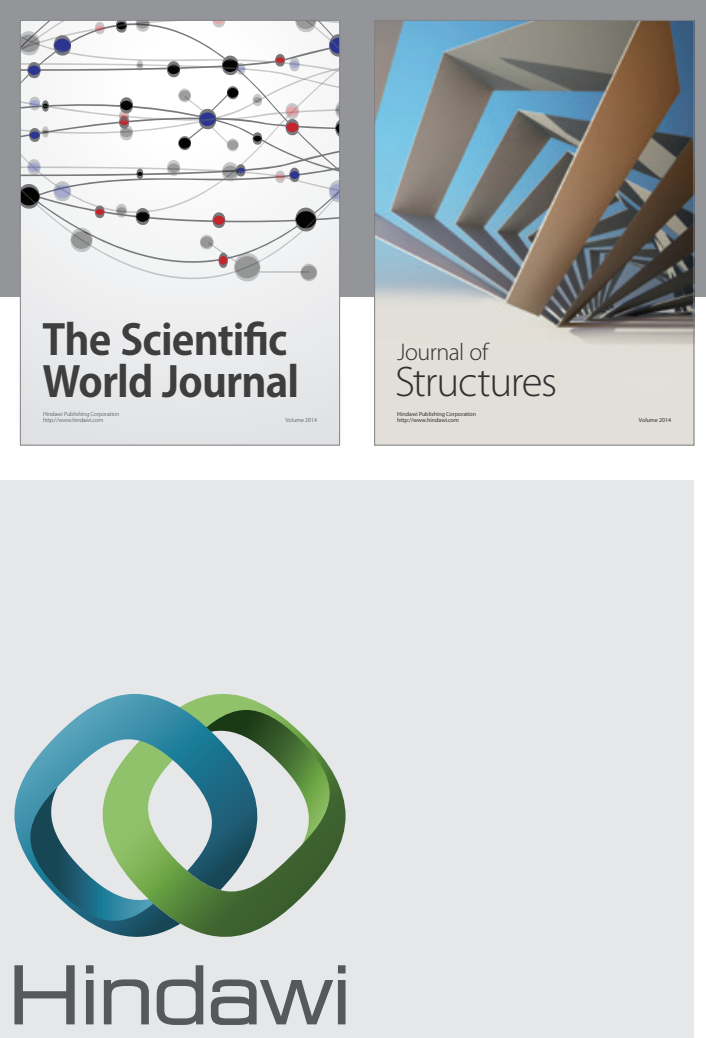

Submit your manuscripts at

http://www.hindawi.com
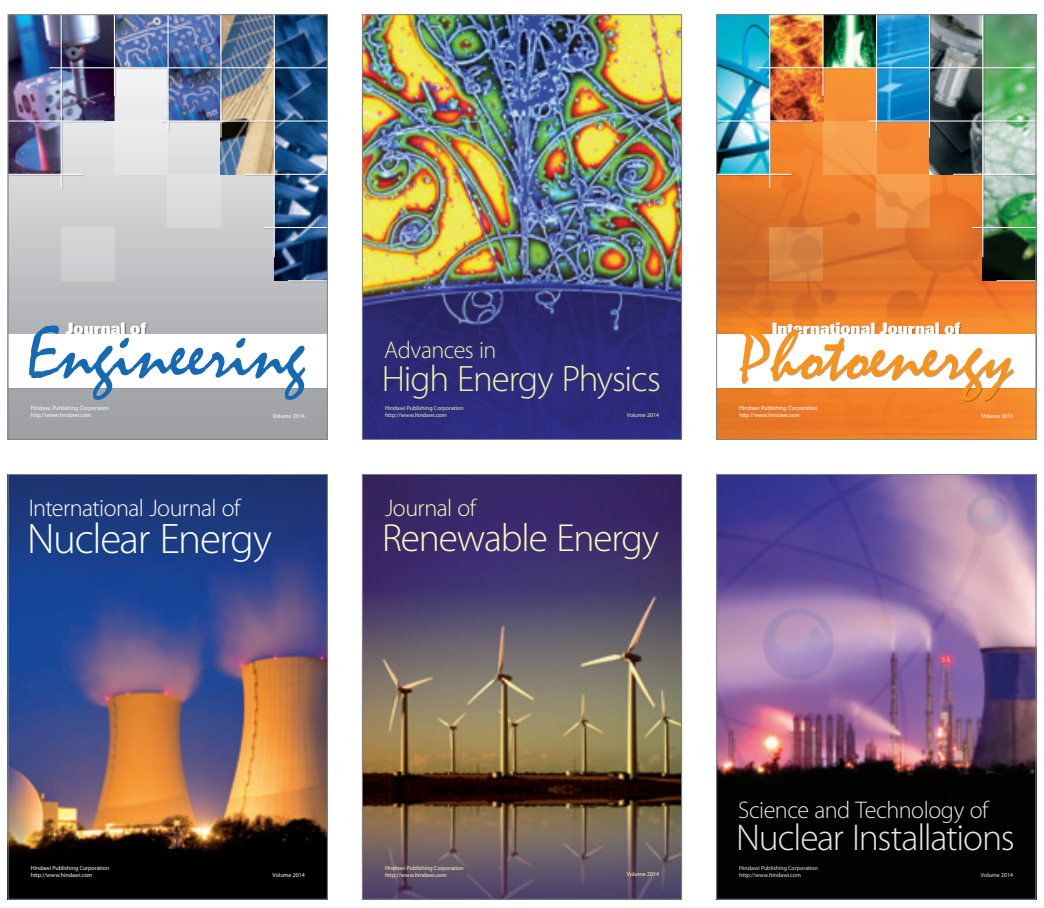
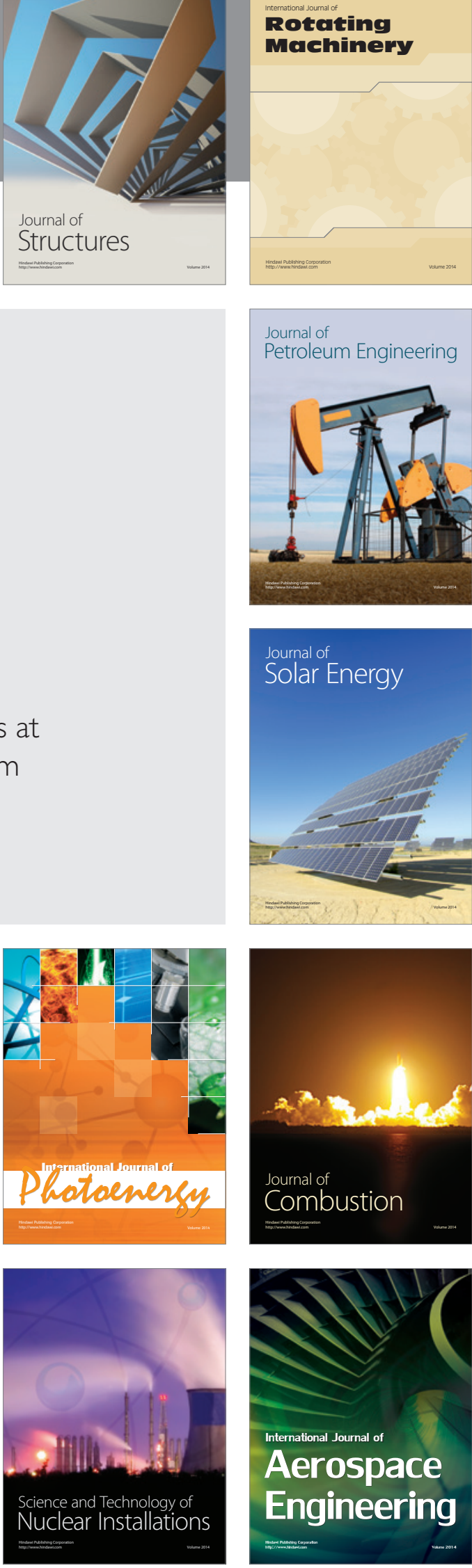